DOI: 10.12731/2070-7568-2017-4-195-207

УДК 332.012.332

\title{
КЛАСТЕРЫ: \\ ОРГАНИЗАЦИОННО-ЭКОНОМИЧЕСКАЯ ПРИРОДА И ОСНОВНЫЕ РАЗНОВИДНОСТИ
}

Солопова Н.В.

В эпоху глобализачии экономики в разных странах мира, и с развитой экономикой, и только развивающихся, широко распространено создание кластеров. Образование кластера дает возможность входящим в него предприятиям использовать потенциил новых технологий, увеличивать сферу своей деятельности, развивать деловые отношения с интересуюшими партнерами, привлечь грамотных квалифицированных работников. Применение в экономике региона кластерного подхода даст возможность повысить конкурентоспособность региона, отрасли, и государства. В статье приведены определения кластера, предложенные зарубежными и отечественными учеными, рассмотрены виды и классификация кластеров. Представлено авторское определение кластера.

Цель - уточнить организачионно-экономическую природу кластера на основе анализа существующих подходов к ее определению.

Метод и методология проведения работы: статья носит обзорный характер и демонстрирует различные взгляды на исследуемую проблему.

Результаты: уточнение понятия «кластер».

Область применения результатов: представленная информаџия дает познавательно-обучающийся обзор теории кластеров, применима для обучения в учебных учреждениях по экономическим направлениям, а также для лич заинтересованных в создании кластера.

Ключевые слова: кластер; регион; развитие; экономика; конкурентоспособность. 


\section{CLUSTERS: \\ ECONOMIC-ORGANIZING NATURE \\ AND ITS MAIN VARIETIES}

\section{Solopova N.V.}

In the era of globalization of economy in the different countries of the world with the developed economy or only developing, the creation of the clusters is widespread. The formation of a cluster gives the chance to the enterprises to use the potential of new technologies, to increase the sphere of the activities, to develop business relations with the partners interesting for us, to involve competent skilled workers. The use of the cluster approach in the economy of the region will give the preferential chance to increase competitiveness of the region, the branch and the state. The definitions of a cluster offered by the foreign and domestic scientists, the types and classification of a cluster are given in the article. Authoring determination of a cluster is provided.

The purpose of the article is to specify the economic-organising nature of a cluster on the basis of the analysis of the existing approaches to its definition.

Method and methodology of the research work: the article is given in the form of an overview and it shows different views on the researched problem.

Results: to specify the notion "a cluster".

Scope of application: the provided information gives the cognitive studying review of the theory of clusters, it is applicable for the training in educational institutions in the economic training and also for those who are interested in the cluster creation.

Keywords: cluster; region; development; economy; competitiveness.

Сегодня в целях создания конкурентоспособности (наличие конкурентоспособных предприятий), повышения уровня доходов населения Регионов, обеспечения дополнительных рабочих мест и усиления конкурентной позиции на внутреннем и мировом рынках во многих российских регионах обратились к кластерной политике [5]. 
Кластерная политика обеспечивает максимально применение существующих в отдельном регионе конкурентных преимуществ, которое достигается организацией и выполнением отдельных видов деятельности и направлена на выход Российских предприятий на лидирующие места в международной конкурентной борьбе. Кластерная политика является действенным инструментом, использование которого предопределяет стимуляцию развития региона, а также повышает статус конкурентоспособности и стабильности промышленности региона, приводящего к увеличению отчислений в бюджет региона и государства, снижается уровень безработицы, повышается уровень заработной платы. Однако для эффективного использования кластерного подхода в интересах российской экономики необходимо ясное понимание природы кластера. Анализ источников показывает, что в настоящее время единого подхода к описанию сущности кластеров нет. Цель данной работы - уточнить понятие «кластер».

Одним из основоположников кластерной теории является Майкл Портер (американский экономист, профессор Гарвардской Школы Бизнеса). Также над проблемой развития и формирования кластеров работают ряд отечественных и зарубежных ученых. При этом теоретические подходы к определению кластеров заметно различаются. Представим в таблице 1 подходы к определению кластера разными учеными.

Таблиияа 1.

Подходы к определению понятия экономический кластер зарубежными и отечественными учеными

\begin{tabular}{|c|c|c|}
\hline $\begin{array}{c}\text { Зарубежные } \\
\text { ученые }\end{array}$ & Определение кластера & $\begin{array}{c}\text { Достоинства и недостатки } \\
\text { предложенных определений }\end{array}$ \\
\hline М. Портер & $\begin{array}{c}\text { Кластер - это группа географи- } \\
\text { чески соседствующих взаимосвя- } \\
\text { занных компаний и связанных с } \\
\text { ними организаций, действующих } \\
\text { в определенной сфере, характе- } \\
\text { ризующихся общностью деятель- } \\
\text { ности и взаимодополняющих друг } \\
\text { друга [10]. }\end{array}$ & $\begin{array}{c}\text { Достоинства: указание } \\
\text { на взаимодополняемость } \\
\text { компаний. } \\
\text { Недостатки: неясно, чем } \\
\text { кластер отличается от дру- } \\
\text { гих территориально-эко- } \\
\text { номических образований } \\
\text { экономики }\end{array}$ \\
\hline
\end{tabular}


Продолжение табл. 1.

\begin{tabular}{|c|c|c|}
\hline С. Розенфельд & $\begin{array}{c}\text { Кластер - это пространственно- } \\
\text { ограниченное число компаний, } \\
\text { имеющих системное дополнение, } \\
\text { либо сходство друг с другом [4]. }\end{array}$ & $\begin{array}{c}\text { Достоинства: системный } \\
\text { характер кластера. } \\
\text { Недостатки: неясно, чем } \\
\text { кластер отличается от дру- } \\
\text { гих территориально-эконо- } \\
\text { мических образований }\end{array}$ \\
\hline Е. Дахмен & $\begin{array}{c}\text { Кластер - совокупность секторов } \\
\text { или «блоков развития» экономики, } \\
\text { где основой развития является } \\
\text { наличие связи между способно- } \\
\text { стью одного сектора развиваться } \\
\text { и обеспечивать прогресс в другом } \\
\text { секторе [1]. }\end{array}$ & $\begin{array}{c}\text { Достоинства: указание на } \\
\text { межотраслевой характер } \\
\text { кластера. } \\
\text { Недостатки: методологи- } \\
\text { чески некорректно гово- } \\
\text { рить об объединении сек- } \\
\text { торов экономики - участ- } \\
\text { никами объединения могут } \\
\text { быть реальные экономиче- } \\
\text { ские агенты; отсутствует } \\
\text { указание на региональную } \\
\text { привязку кластера. }\end{array}$ \\
\hline В. Фельдман & $\begin{array}{c}\text { Кластер - диверсифицированная } \\
\text { совокупность отраслей, связанных } \\
\text { отношениями поставок и приоб- } \\
\text { ретений, основанных на матрице } \\
\text { «затраты - выпуск» [6]. }\end{array}$ & $\begin{array}{c}\text { Достоинства: указание на } \\
\text { экономическую модель } \\
\text { функционирования кла- } \\
\text { стера. } \\
\text { Недостатки: неясен со- } \\
\text { став участников кластера; } \\
\text { отсутствует указание на } \\
\text { региональную привязку } \\
\text { кластера. }\end{array}$ \\
\hline $\begin{array}{l}\text { Отечествен- } \\
\text { ные ученые }\end{array}$ & Определение кластера & $\begin{array}{c}\text { Достоинства и недостатки } \\
\text { предложенных определений }\end{array}$ \\
\hline Д.А. Ялов & $\begin{array}{c}\text { Кластер - это сеть поставщиков, } \\
\text { производителей потребителей, } \\
\text { элементов промышленной инфра- } \\
\text { структуры, исследовательских } \\
\text { институтов, взаимосвязанных в } \\
\text { процессе создания прибавочной } \\
\text { стоимости [8]. }\end{array}$ & $\begin{array}{c}\text { Достоинства: указание на } \\
\text { сетевой характер кластера; } \\
\text { указание на вовлечение } \\
\text { некоммерческих органи- } \\
\text { заций в процесс создания } \\
\text { добавленной стоимости } \\
\text { Недостатки: смешение в } \\
\text { одном определении ин- } \\
\text { ституционального (сети) и } \\
\text { марксистского (прибавоч- } \\
\text { ная стоимость) подходов; } \\
\text { отсутствует указание на } \\
\text { региональную привязку } \\
\text { кластера. }\end{array}$ \\
\hline
\end{tabular}


Окончание табл. 1.

\begin{tabular}{|c|c|c|}
\hline $\begin{array}{c}\text { А.А. Мигра- } \\
\text { нян }\end{array}$ & $\begin{array}{c}\text { Кластер - это сосредоточение } \\
\text { наиболее эффективных и взаимос- } \\
\text { вязанных видов экономической } \\
\text { деятельности, т.е. совокупность } \\
\text { взаимосвязанных групп, успешно } \\
\text { конкурирующих фирм, которые } \\
\text { образуют «золотое сечение» всей } \\
\text { экономической системы государ- } \\
\text { ства и обеспечивают конкурент- } \\
\text { ные позиции на отраслевом, наци- } \\
\text { ональном и мировом рынках [2]. }\end{array}$ & $\begin{array}{c}\text { Достоинства: указание как } \\
\text { на межотраслевой харак- } \\
\text { тер кластера, так и на со- } \\
\text { став его участников. } \\
\text { Недостатки: не ясно, что } \\
\text { имеет автор под «золотым } \\
\text { сечением»; отсутствует } \\
\text { указание на присутствие в } \\
\text { кластере некоммерческих } \\
\text { структур; отсутствует } \\
\text { указание на региональную } \\
\text { привязку кластера. }\end{array}$ \\
\hline Т.В. Цихан & $\begin{array}{l}\text { Кластер - это сообщество фирм, } \\
\text { тесно связанных отраслей, взаим- } \\
\text { но способствующих росту конку- } \\
\text { рентоспособности друг друга [7]. }\end{array}$ & $\begin{array}{c}\text { Достоинства: есть указа- } \\
\text { ние на синергетический } \\
\text { эффект кластера. } \\
\text { Недостатки: Не охвачена } \\
\text { деятельность НИИ; от- } \\
\text { сутствует указание на } \\
\text { региональную привязку } \\
\text { кластера. } \\
\end{array}$ \\
\hline В.П. Третьяк & $\begin{array}{c}\text { Кластер - указывает на отрасле- } \\
\text { вую и географическую концентра- } \\
\text { цию предприятий, которые про- } \\
\text { изводят и продают ряд связанных } \\
\text { или взаимодополняемых товаров } \\
\text { совместными усилиями [9]. }\end{array}$ & $\begin{array}{c}\text { Достоинства: констатация } \\
\text { отраслевой и географи- } \\
\text { ческой привязки участ- } \\
\text { ников кластера, описание } \\
\text { характера деятельности } \\
\text { кластера. } \\
\text { Недостатки: Не охвачена } \\
\text { деятельность НИИ. }\end{array}$ \\
\hline $\begin{array}{l}\text { М.Ю. Шере- } \\
\text { шева }\end{array}$ & $\begin{array}{c}\text { кластер есть группа предприятий, } \\
\text { которые не просто соседствуют } \\
\text { территориально, но объединяются } \\
\text { в сеть, нацеленную на достижение } \\
\text { определенного общего результата, } \\
\text { причем, как правило, в этой сети } \\
\text { необходимо присутствие ком- } \\
\text { паний, представляющих разные } \\
\text { отрасли (не случайным образом, а } \\
\text { по принципу комплементарности } \\
\text { ресурсов и компетенций) [11]. }\end{array}$ & $\begin{array}{c}\text { Достоинства: указание на } \\
\text { сетевой характер кластера } \\
\text { и на его территориальную } \\
\text { привязку. Недостатки: Не } \\
\text { охвачена деятельность НИИ. }\end{array}$ \\
\hline $\begin{array}{c}\text { Ю. Б. Минд- } \\
\text { лин }\end{array}$ & $\begin{array}{l}\text { Сети, состоящие из сетевых струк- } \\
\text { тур (сформированных, в свою оче- } \\
\text { редь, из коммерческих и некоммер- } \\
\text { ческих организаций) и имеющие } \\
\text { территориальную привязку [14] }\end{array}$ & $\begin{array}{c}\text { Достоинства: описывает ос- } \\
\text { новные признаки кластера } \\
\text { Недостаток: нет указания } \\
\text { на синергетический эф- } \\
\text { фект кластера }\end{array}$ \\
\hline
\end{tabular}


Существуют виды кластеров по разным признакам. Проанализировав типы кластеров, выделим определенные, наиболее применимые в экономике нашей страны и региона виды кластера, которые показаны в таблице 2 .

Таблицуа 2.

Виды кластеров

\begin{tabular}{|c|c|c|}
\hline $\begin{array}{c}\text { Вид } \\
\text { кластера }\end{array}$ & Специфика кластера & $\begin{array}{c}\text { Пример существу- } \\
\text { ющих кластеров }\end{array}$ \\
\hline $\begin{array}{l}\text { Региональ- } \\
\text { ный }\end{array}$ & $\begin{array}{l}\text { Это ассоциация предприятий, которые } \\
\text { взаимосвязаны между собой по роду } \\
\text { деятельности и функционирующие } \\
\text { территориально внутри региона. Ре- } \\
\text { гиональный кластер способствует } \\
\text { увеличению конкурентоспособности } \\
\text { предприятий, повышению доли добав- } \\
\text { ленной стоимости от реального сектора } \\
\text { экономики. Поднимет уровень жизни } \\
\text { населения, позволит комплексно ис- } \\
\text { пользовать экономический потенциал } \\
\text { региона. }\end{array}$ & $\begin{array}{l}\text { Текстильный кла- } \\
\text { стер, Ивановская } \\
\text { область. } \\
\text { Более } 10 \text { мелких и } \\
\text { средних предпри- } \\
\text { ятий одного профи- } \\
\text { ля [5]. }\end{array}$ \\
\hline $\begin{array}{l}\text { Вертикаль- } \\
\text { ный }\end{array}$ & $\begin{array}{l}\text { К- Кластеры с вертикальными производ- } \\
\text { ственными связями в определенных } \\
\text { сферах деятельности, образованные } \\
\text { вокруг головных фирм или ряда } \\
\text { основополагающих предприятий, } \\
\text { охватывающие процесс производства, } \\
\text { поставку и сбыт, а также ремонт и сер- } \\
\text { висное обслуживание, характеризуют- } \\
\text { ся как иерархическая связь сопредель- } \\
\text { ных ступеней производственного или } \\
\text { инновационного процесса, где предус- } \\
\text { мотрено наличие инфраструктурного, } \\
\text { кооперационного и агломерационного } \\
\text { эффекта. Объединение предприятий в } \\
\text { одну цепочку для создания стоимости, } \\
\text { себестоимость выпускаемого продук- } \\
\text { та снизится, при выполнении крупных } \\
\text { многосерийных заказов. }\end{array}$ & $\begin{array}{l}\text { Самарский автомо- } \\
\text { бильный кластер. } \\
\text { Одна профильная } \\
\text { компания - Авто- } \\
\text { Ваз, автосборочное } \\
\text { СП «Джи Эм- } \\
\text { Авто-ВАЗ», } 700 \\
\text { производителей } \\
\text { автокомпонентов, } \\
\text { предприятия авто- } \\
\text { сервиса и торговли, } \\
\text { исследовательские, } \\
\text { конструкторские, } \\
\text { технологические, } \\
\text { консалтинговые, } \\
\text { финансовые орга- } \\
\text { низации, образова- } \\
\text { тельные учрежде- } \\
\text { ния [5]. }\end{array}$ \\
\hline
\end{tabular}


Окончание табл. 1.

\begin{tabular}{|c|c|c|}
\hline Отраслевой & $\begin{array}{l}\text { - Данное объединение, включает в } \\
\text { себя отраслевые компании, которые } \\
\text { взаимодействуют со смежными орга- } \\
\text { низациями. Основополагающей функ- } \\
\text { цией в их сотрудничестве являются } \\
\text { конкурентные и кооперационные взаи- } \\
\text { моотношения. Где увеличение эффек- } \\
\text { тивности деятельности предприятий, } \\
\text { вследствие объединения их в единую } \\
\text { систему, дает эффект возрастания кон- } \\
\text { курентных преимуществ. }\end{array}$ & $\begin{array}{l}\text { Алтайский био- } \\
\text { фармацевтический } \\
\text { кластер, г. Бийск. } \\
\text { Около } 30 \text { сельско- } \\
\text { хозяйственных, } \\
\text { производственных, } \\
\text { научно-исследова- } \\
\text { тельских организа- } \\
\text { ций [5]. }\end{array}$ \\
\hline $\begin{array}{l}\text { Горизонталь- } \\
\text { ный }\end{array}$ & $\begin{array}{l}\text { - Объединяет разные отраслевые пред- } \\
\text { приятия промышленности в единую } \\
\text { систему функцонирования, для до- } \\
\text { стижения поставленной задачи. }\end{array}$ & $\begin{array}{l}\text { Агропромышлен- } \\
\text { ный кластер вклю- } \\
\text { чает в себя: } \\
\text { - сельскохозяй- } \\
\text { ственные предпри- } \\
\text { ятия - поставщики } \\
\text { сырья; - предпри- } \\
\text { ятия сельскохозяй- } \\
\text { ственного машино- } \\
\text { строения - постав- } \\
\text { щики оборудования. }\end{array}$ \\
\hline $\begin{array}{l}\text { Промышлен- } \\
\text { ный }\end{array}$ & $\begin{array}{l}\text { - } \text { В состав кластера входят предпри- } \\
\text { ятия, с всевозможными, ресурсами и } \\
\text { видами деятельности, объединяющие- } \\
\text { ся для развития, производства и сбыта } \\
\text { разных видов товаров и услуг. Про- } \\
\text { мышленный кластер не ограничивает } \\
\text { свои связи территориально, а имеет } \\
\text { тенденцию на свободные границы, } \\
\text { включая страну. }\end{array}$ & $\begin{array}{l}\text { Промышленный кла- } \\
\text { стер по производству } \\
\text { бытовой техники, } \\
\text { Липецкая область. } \\
\text { Одно крупное пред- } \\
\text { приятие - 3АО «Ин- } \\
\text { дезит», } 12 \text { предпри- } \\
\text { ятий поставщиков } \\
\text { [5]. } \\
\text { Оборонно-промыш- } \\
\text { ленный включает в } \\
\text { себя: разработку и - } \\
\text { испытание продукта } \\
\text { - специальные науч- } \\
\text { ные учреждения; } \\
\text { - заводы по выпуску } \\
\text { составляющих про- } \\
\text { дукт; - заводы по } \\
\text { созданию конечного } \\
\text { продукта). }\end{array}$ \\
\hline
\end{tabular}


Изучая, существующие виды кластеров, приведенные в разных источниках многими экономистами и имея различные толкования можно выделить классификацию кластеров по разным критериям, наиболее соответствующие для России:

- Географический - территориально ограниченный кластер, масштаб которого зависит от особенностей производства, он может охватывать как один, так и несколько регионов государства. Географическая близость обеспечивает быстроту и небольшие затраты на поставку потребного сырья для производства. В качестве примера для местного производства, можно рассмотреть рыбную промышленность; а более масштабного - аэрокосмическое производство;

- Латеральный - объединяет в кластер разные подразделения одной отрасли, обеспечивая экономию собственных средств за счет эффекта масштаба производства, что практически дает новые возможности. Для примера можно привести косметическое производство;

- Технологический - выражается в объединении производств, которые связаны общей технологией. Такие кластеры имеют тенденцию развитию в инновационной сфере. Примером может послужить: производство потребительской электроники, программное обеспечение, биотехнологии;

- Фокусный - это кластер организаций, сконцентрированный в центре одного главного значительного предприятия, учебного центра, ВУЗа, НИИ;

- Качественный - кластер, совершенствующийся в разных видах деятельности, что ведет к повышению конкурентоспособности каждого в отдельности предприятия и от этого улучшается экономическая ситуация кластера в целом. Пример - производство обуви;

- Транснациональный - в состав кластера входят отечественные и иностранные предприятия, положительной стороной которых в отличае от холдинга или других международных объединяющих организаций, является сохранение за пред- 
приятиями статуса юридического лица, за счет неполного слияния между собой и взаимодействия по определенному уставу. Пример - производство швейных машин, где сборка отечественная, а комплектующие импорт;

- Национальный - объединяются несколько предприятий из разных регионов страны, где организацию развития производства осуществляет специализированная организация. Пример - ООО «Национальный аэрозольный кластер», в данный момент участники кластера составляют 11 предприятий с разных регионов страны;

- Инновационный - объединяет в себе некоторое число современных компаний, формирующихся на стадии расширения новых коммерческих технологий и результативности в научной деятельности, осуществляемые в ВУЗах и других исследовательских учреждениях. Пример - информационные технологии, биотехнологии, нанотехнологии.

На основе выполненного выше анализа автором предлагается свое определение кластера.

Кластер - это объединение предприятий, в том числе и научно-исследовательских учреждений, которые не ограниченны географически и характеризуются по (специализированному) определенному признаку или виду деятельности, занимающиеся одним общим производством и реализацией выпускаемого продукта, на региональном, государственном, межнациональном или мировом уровне.

В этом определении уточнено наличие НИИ в формировании кластера. Автор считает, что НИИ обязательно должны присутствовать в кластерах, так как в эпоху глобализации и появления новых технологий, ученые специалисты должны постоянно усовершенствовать производимый продукт кластера, чтобы он был конкурентоспособный. Также многие экономисты рассматривают кластер внутри региона, в авторском определении возможны варианты создания кластера на региональном, государственном, межнациональном или мировом уровне, что может увеличить масштабы 
производства, повысить качество выпускаемого продукта и расширить границы его продвижения, поднять престиж компании за счет конкурентоспособного производства. Если в объединение кластера войдут разные страны, это поднимет престиж не только предприятия, но и страны, что приведет к развитию экономики.

Таким образом, автор утверждает, что кластерные эффекты могут проявляться не только на региональном уровне, и сведение кластеров к структурам, имеющим жесткую региональную привязку, искусственно обедняет понятие кластера. Очевидно, что в настоящее время, когда производственные цепочки носят глобальный характер, даже территориально локализованный кластер сотрудничает с рядом предприятий и организаций из других регионов и стран, и поэтому отказ от жесткой привязки кластеров к конкретному региону вполне оправдан.

С развитием глобальной экономики и появлением глобальных коммуникационных систем предприятия виртуализируются, а фирма трансформируется в метафирму [11-13]. Она основывается на следующих позициях:

1) нарушается территориальная целостность предприятия, потому что нет необходимости производить самому какие-то комплектующие детали, если есть возможность заказать у тех, кто может произвести их лучше, с меньшей стоимостью и в короткие сроки;

2) компаньоны по производству общего продукта могут существовать, пока их продукт отвечает стандартам качества и новым технологичным уровням;

3) поиск компаньонов в глобальной экономике должен охватывать весь мир;

4) предприятию выгодно иметь гибкую структуру, с наибольшей эффективностью применяя имеющиеся и получаемые ресурсы;

5) с развитием новых технологий нерентабельно вкладывать денежные средства в приобретение оборудования и других побочных средств для создания нового производства, при условии неизвестности выпуска объема продукции. 


\section{Сиисок литературы}

1. Прокофьев К.Ю. Место территориальных кластеров в механизме инновационного развития регионов // Инновации и инвестиции. 2013. №14.

2. Мигранян А.А. Теоретические аспекты формирования конкурентоспособных кластеров в странах с переходной экономикой // Вестник КРСУ. 2002. №3.

3. Майкл Э. Портер. Конкуренция. Пер. с англ. М.: Издательский дом «Вильямс», 2005. 608 с.

4. Розенфельд С. Кластер: стратегии экономического развития. Карборо, NC: Региональные Технологические Стратегии, Inc, 2002.

5. Угрюмова А.А. Региональная экономика и управление. Учебник и практикум для бакалавриата и магистратуры / А.А. Угрюмова, Е.В. Ерохина, М.В. Савельева. ООО «Издательство Юрайт», 2016.

6. Фельдман В.П. Инновации в городах: Наука, основывающаяся на разнообразии, специализации и локализации конкуренции // Европейский экономический обзор. 1999. № 43. С. 409-429.

7. Цихан Т.В. Кластерная теория экономического развития // Теория и практика управления. 2003. №5.

8. Ялов Д.А. Кластерный подход как технология управления региональным экономическим развитием. СПб: Фонд ЦСР «Северо-Запад», 2006.

9. Третьяк В.П. Кластеры предприятий: пути создания и результативность функционирования [Электронный ресурс]. http://ecsocman. hse.ru/text/16210559/

10. Porter M.E. On Competition. Harvard Business School Press: Boston. 1998.

11. Шерешева М.Ю. Формы сетевого взаимодействия компаний. М.: Изд. дом Гос. ун-та - Высшая школа экономики, 2010. 339 с.

12. Котляров И.Д. Метафирма как форма организации хозяйственной деятельности // Управление экономикой: методы, модели, технологии. Материалы XV Международной научной конференции. В 2 томах. Т. 1. Уфимский государственный авиационный технический университет: Уфа, 2015. С. 88-91. 
13. Бугорский В.Н. Сетевая экономика. М.: Финансы и статистика, 2008. $256 \mathrm{c}$.

14. Миндлин Ю.Б. Кластер: анализ экономико-организационной природы // Современная наука: актуальные проблемы теории и практики. Серия: Экономика и право. 2015. № 3-4. С. 31-34.

\section{References}

1. Prokof’ev K.Yu. Innovatsii i investitsii. 2013. №14.

2. Migranyan A.A. Vestnik KRSU. 2002. №3.

3. Maykl E. Porter. Konkurentsiya [Competition]. M.: Izdatel'skiy dom «Vil'yams», 2005. 608 p.

4. Rozenfel'd S. Klaster: strategii ekonomicheskogo razvitiya [Cluster: strategies for economic development]. Karboro, NC: Regional'nye Tekhnologicheskie Strategii, Inc, 2002.

5. Ugryumova A.A., Erokhina E.V., Savel'eva M.V. Regional'naya ekonomika i upravlenie. Uchebnik i praktikum dlya bakalavriata i magistratu$r y$ [Regional economy and management. Textbook and workshop for undergraduate and graduate students]. OOO «Izdatel'stvo Yurayt», 2016.

6. Fel'dman V.P. Evropeyskiy ekonomicheskiy obzor. 1999. № 43, pp. 409-429.

7. Tsikhan T.V. Teoriya i praktika upravleniya. 2003. №5.

8. Yalov D.A. Klasternyy podkhod kak tekhnologiya upravleniya regional'nym ekonomicheskim razvitiem [Cluster approach as a technology for managing regional economic development]. SPb: Fond TsSR «Severo-Zapad», 2006.

9. Tret'yak V.P. Klastery predpriyatiy: puti sozdaniya i rezul'tativnost' funktsionirovaniya [Clusters of enterprises: ways of creation and effectiveness of functioning]. http://ecsocman.hse.ru/text/16210559/

10. Porter M.E. On Competition. Harvard Business School Press: Boston. 1998.

11. Sheresheva M.Yu. Formy setevogo vzaimodeystviya kompaniy [Forms of network interaction of companies]. M.: Izd. dom Gos. un-ta - Vysshaya shkola ekonomiki, 2010. 339 p.

12. Kotlyarov I.D. Upravlenie ekonomikoy: metody, modeli, tekhnologii. Materialy XV Mezhdunarodnoy nauchnoy konferentsii [Management of 
the economy: methods, models, technologies. Materials of the XV International Scientific Conference]. V. 1.Ufa, 2015, pp. 88-91.

13. Bugorskiy V.N. Setevaya ekonomika [Networking Economics]. M., 2008. $256 \mathrm{p}$.

14. Mindlin Yu. B. Sovremennaya nauka: aktual'nye problemy teorii i praktiki. Seriya: Ekonomika i pravo. 2015. № 3-4, pp. 31-34.

\section{ДАННЫЕ ОБ АВТОРЕ}

Солопова Надежда Владимировна, аспирант кафедры «Региональная экономика»

Оренбургский государственный университет пр. Победы 13, г. Оренбург, 460026, Российская Федеращия solopova.nad@mail.ru

\section{DATA ABOUT THE AUTHOR}

Solopova Nadezhda Vladimirovna, Postgraduate Student of the Department "Regional Economy" Orenburg State University 13, Pobedy, Orenburg, 460026, Russian Federation solopova.nad@mail.ru 